\title{
Why do we need Human Systems Management?
}

We live in the world of information overload. Why do we need another journal, any journal, to add to the hundreds of those pertaining to management in one way or another? This is a valid and serious question and HSM initiators and editors spent many years discussing it before deciding to bring this journal into existence.

Each of us, who has some interface with the management of human systems, is a specialist, expert or a professional in one or more specific areas of management. We are financial managers, computer scientists, planners, market analysts, operations researchers, statisticians, business lawyers, industrial psychologists, engineers, technologists, systems analysts, and so on. We also function as consultants, entrepreneurs, economists, futurists, environmental analysts, policy makers, educators, public administrators, or political activists. Each of us probably subscribes to at least one journal or magazine within our particular area of specialty or interest. There is certainly no lack of choice - even the narrowest specialty area is likely to be covered by several journals at the same time. You have undoubtedly selected your first journal(s) by now.

HSM aspires to become your second most important journal - to be read in your quest for becoming a well-rounded, knowledgable and self-confident specialist. In order to be a good specialist or expert, one must be able to move beyond one's own specialty.
One must be able to learn to communicate with, to understand and to integrate all of the other specialists of management. Directly or indirectly we encounter these people and our effectiveness can only be enhanced by knowing their language, current concerns, and critical issues.

That is what we mean by the transdisciplinarity of HSM. HSM is important because it aspires to reach all specialists within the management community and make them aware of the broader framework within which they operate and can become effective. We all know how to become better specialists. But how to become effective, influential and useful specialists that requires transcending our individual disciplines of interest and expertise.

The world of management is becoming complex and interconnected, its problems are multi-faceted and constantly shifting in their dominant characteristics. An expert specialized view, although necessary, is no longer sufficient. HSM identifies human beings, as individuals or organized groups, as a single common denominator of most managerial concerns. It is from this vantage point that HSM will attempt to communicate across all managerial disciplines.

Your first specialty journal is obviously necessary but it is probably not sufficient; HSM is designed to close the gap through becoming your second most important journal. 